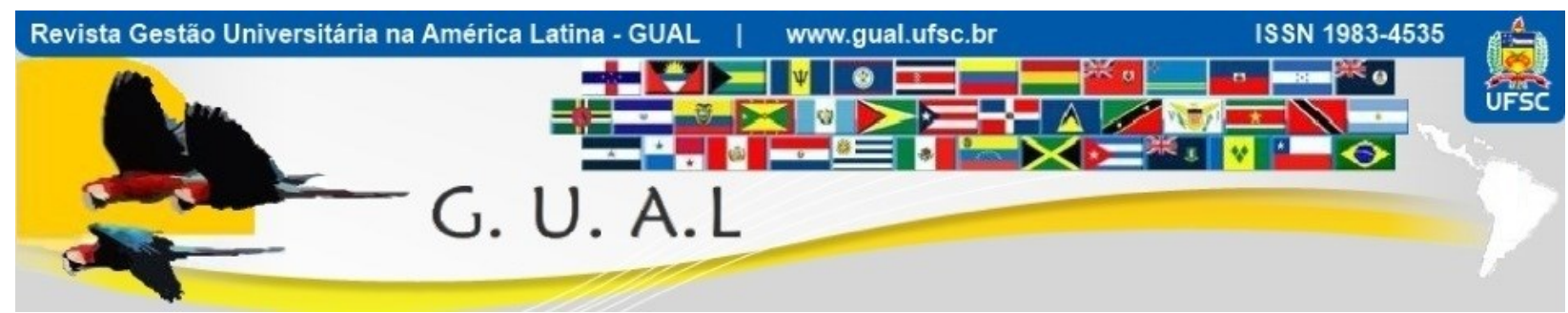

DOI: http://dx.doi.org/10.5007/1983-4535.2020v13n3p232

\title{
GESTÃO DE RISCOS NA ÁREA DE PESSOAL À LUZ DA EMENDA CONSTITUCIONAL 95/2016: UMA APLICAÇÃO PARA A UNIVERSIDADE DE BRASÍLIA
}

\author{
RISK MANAGEMENT IN THE PERSONNEL AREA UNDER THE \\ CONSTITUTIONAL AMENDMENT 95/2016: AN APPLICATION FOR THE \\ UNIVERSITY OF BRASÍLIA
}

Fernanda Leite Ferreira da Silva, Mestre http://orcid.org/0000-0001-7379-3636 fleite74@gmail.com Universidade de Brasília | Programa de Pós-graduação em Gestão Pública Brasília | Distrito Federal | Brasil

Alexandre Nascimento de Almeida, Doutor http://orcid.org/0000-0002-9113-0729 alexalmeida@unb.br

Universidade de Brasília | Programa de Pós-graduação em Gestão Pública Brasília | Distrito Federal | Brasil

Recebido em 29/março/2020

Aprovado em 17/julho/2020

Publicado em 01/setembro/2020

Sistema de Avaliação: Double Blind Review

Esta obra está sob uma Licença Creative Commons Atribuição-Uso. 


\title{
RESUMO
}

A Fundação Universidade de Brasília - FUB gastou $84 \%$ de seus recursos com o pagamento de pessoal em 2018, restando uma margem restrita para reposição de vagas geradas pelas aposentadorias dos servidores, dadas as restrições da EC 95/2016. Esse cenário impacta a área de recursos humanos, justificando o objetivo de analisar os riscos na área de gestão de pessoas na Universidade de Brasília. Para tanto, pela ponderação entre os dados da probabilidade dos riscos com os dados das suas magnitudes, estimou-se o nível de criticidade dos riscos. Dos 29 riscos da área de pessoal identificados, $86 \%$ foram considerados de nível crítico ou alto, estando esses concentrados nas áreas de gestão, em especial na identificação deficiente da força de trabalho e dos perfis dos servidores. A partir dos riscos encontrados, conclui-se que a FUB não está suficientemente preparada para fazer frente aos problemas na área de pessoal.

Palavras-chave: Governança. Gestão Universitária. Administração Pública.

\begin{abstract}
The Fundação Universidade de Brasília - FUB spent $84 \%$ of its resources with the payment of staff in 2018, leaving a restricted margin for replacing vacancies generated by the retirements of civil servants, given the restrictions of EC 95/2016. This scenario impacts the human resources area, justifying the objective of analyze the risks in the people management area at the University of Brasilia. Therefore, by multiplying the data from probability of risks with the data of their magnitudes the level of critical risk was estimated. Of the 29 personnel area risks identified, $86 \%$ were considered to be of a critical or high level, being concentrated in the management areas, especially in the deficient identification of the workforce and profiles of the employees. Based on the risks found, the conclusion is that the FUB is not sufficiently prepared to face the problems in the personnel area.
\end{abstract}

Keywords: Governance. University Management. Public Administration. 


\section{INTRODUÇÃO}

Apesar de os últimos cinco anos, a partir de 2014, terem se caracterizado por anos de baixo crescimento econômico, observou-se um aumento contínuo dos gastos obrigatórios do governo federal, em especial em despesas de pessoal, previdência e dívida pública. Nesse contexto, surgiu a Emenda Constitucional - EC 95/2016 que previu, entre outras coisas, o controle de gastos públicos até 2036 (Brasil, 2016).

Essa emenda impôs que os orçamentos globais dos órgãos federais, inclusive as Instituições Federais de Ensino - IFES, passem a ser incrementados anualmente apenas pela inflação. Consequentemente, existe um risco para a continuidade de algumas atividades das IFES haja vista que haverá pouca margem para contratar novos servidores para repor aqueles que aposentarem nos próximos anos, pois, mesmo quando um servidor aposenta, os gastos com sua aposentadoria continuam como parte da folha de pagamento da instituição.

Ao comparar as despesas com pessoal e encargos, de 2013 a 2017, observou-se um incremento de $73,4 \%$. Por sua vez, o orçamento referente às outras despesas correntes (água, luz e manutenção) e ao investimento apresentaram queda de $37,6 \%$ e $42,7 \%$, respectivamente (Universidade de Brasília - UnB, 2018a).

Esse quadro se torna muito problemático, tendo em vista que o quadro geral de pessoal da Fundação Universidade de Brasília - FUB está envelhecido e possui grandes perspectivas de aposentadoria nos próximos anos, somado a limitação imposta pela EC 95/2016 ao limitar o teto de gasto, a possibilidade de reposição do contingente de servidores torna-se reduzida.

Portanto, a FUB se encontra em um cenário crítico que poderá afetar a continuidade de seus objetivos, destacando: gastos com pessoal que se encontram em um elevado patamar, impossibilitando a transferência de recursos de outras rubricas (despesas correntes e investimentos) para complementá-lo; estimativas de aposentadorias em um grande volume nos próximos anos (segundo o Plano de Desenvolvimento Institucional - PDI 2018/2022, mais de $46 \%$ dos servidores tem mais de 45 anos); baixa probabilidade de reposição da força de trabalho e de incrementos do orçamento da instituição (UnB, 2018b).

Resta claro, portanto, o risco da FUB no tocante a sua área de pessoal. O quadro de pessoal é o principal ativo/insumo de todas as IFES, sendo que qualquer impacto sobre a disponibilidade da força de trabalho de professores e de técnicos poderá impactar fortemente o seu desempenho e a sua continuidade. Assim, entende-se como um dos principais riscos 
para a continuidade da FUB a diminuição da oferta da força de trabalho que será imposta pela EC 95/2016.

Portanto, as organizações públicas em geral, especificamente a FUB, necessitam gerenciar riscos, identificando-os, analisando-os e, em seguida, avaliando se eles devem ser modificados por algum tratamento, de maneira a propiciar que os objetivos sejam alcançados. Dessa forma, quando se menciona a necessidade de controle de riscos para permitir o atingimento de objetivos das organizações, tem-se como meta melhorar os aspectos de governança da instituição (TCU, 2014).

Resta clara a oportunidade e a relevância de se avaliar a gestão de riscos da área de pessoal da FUB. Assim, buscar-se-á avaliar se a FUB está preparada para gerenciar os riscos afetos à gestão de pessoal, hierarquizando os riscos e fornecendo subsídios para a tomada de decisão.

Por oportuno, dadas as similaridades entre as variáveis de contexto e os processos de trabalho comuns, cabe destacar que a análise a ser realizada poderá ser extrapolada, guardadas as devidas limitações, para outras IFES. Além disso, outro elemento que justifica a pesquisa é a carência de pesquisas na temática abordada, conforme apontado por Ribeiro (2017). Esse autor, após investigar o perfil e as particularidades da produção acadêmica no tema de gestão de riscos, concluiu que as principais abordagens focaram no risco de crédito, risco de preço, risco e retorno e risco financeiro. Assim, Ribeiro (2017) concluiu como oportunidade a realização de pesquisas em outras 25 temáticas relacionadas com a gestão de riscos, incluindo na área de pessoal.

\section{REFERENCIAL TEÓRICO}

\subsection{GESTÃO DE RISCOS}

Segundo as referências sobre gestão de riscos, diversos aspectos internos e externos às organizações podem afetar a sua capacidade de atingir as suas respectivas finalidades, impactando, portanto, a sua efetividade. Todas as organizações estão sujeitas a riscos relativos ao ambiente externo que atuam, ao dinamismo da economia e a fatores internos relacionados a seus insumos e a sua própria gestão, dentro dessa problemática, Ching e Colombo (2013) avaliaram a adoção de boas práticas de gestão de riscos em dez organizações.

Ávila (2014) comenta que a decisão acerca de como equacionar os benefícios e perdas potenciais é o aspecto marcante da gestão de riscos. Corroborando essa afirmativa, Dionne

Revista GUAL, Florianópolis, v. 13, n. 3, p. 232-255, setembro-dezembro 2020 www.gual.ufsc.br @® 
(2013) salienta que a gestão do risco permite diminuir a probabilidade e o impacto de eventos negativos e aumentar as chances de eventos positivos.

A título de apresentar as referenciais na área de risco, o Committee of Sponsoring Organizations of the Treadway Commission - COSO do Institute of Internal Auditors - IIA (2013) publicou em 1992 o guia Internal Control - Integrated Framework (COSO-IC ou COSO I) com a intenção de orientar as organizações quanto aos princípios e as melhores práticas de gestão de riscos e de controle interno. Em 2004 o COSO publicou o Enterprise Risk Management - integrated framework (COSO II), modelo de referência que ultrapassou o COSO I. Além do COSO, destaca-se a norma técnica ISO 31.000 que foi publicada no Brasil sob o nome ABNT NBR ISO 31000:2009 Gestão de riscos - princípios e diretrizes (ISO 31.000, 2009; TCU, 2018b).

Nessa esteira, o Ministério do Planejamento, Desenvolvimento e Gestão - MP (2013) pelo documento Guia de Orientação para Gerenciamento de Riscos, ressalta que os níveis de riscos vêm aumentando globalmente em todas as categorias, exigindo assim, das organizações, cada vez mais capacidade de lidar com altos graus de riscos em seus planos estratégicos, programas, projetos e processos finalísticos, o que vale tanto para o setor público quanto para o setor privado.

O Guia de Orientação para o Gerenciamento de Riscos do MP (2013) classifica os riscos com base na origem dos eventos internos ou externos. Os riscos externos são associados ao ambiente onde a organização atua. Os riscos internos são os relacionados à estrutura da instituição, seus processos, governança, quadro de pessoal, recursos financeiros e ambiente de tecnologia.

Por sua vez, em 2018, o TCU publicou o Guia de Avaliação da Maturidade da Gestão de Riscos, consolidando as informações de diversas fontes nacionais e internacionais em um documento a ser aplicado pelos gestores e auditores responsáveis por implementar e avaliar o risco nas instituições (TCU, 2018c).

Para De Cicco (2018), no que tange aos atributos para uma boa prática na gestão de riscos da organização, podem ser destacados, entre outros aspectos, a capacidade de avaliação e tratamento de riscos. Segundo o autor, esse processo constitui-se de três etapas importantes: a identificação, a análise e a avaliação dos riscos. 


\subsection{GESTÃO DE RISCO EM INSTITUIÇÕES FEDERAIS DE ENSINO SUPERIOR}

Souza e Fernandes (2008) verificou, por meio da matriz de importância e desempenho de Slack, quais são os riscos considerados mais importantes pelas universidades e centros universitários de Santa Catarina, e qual a satisfação dos gestores em relação à gestão desses riscos. Foram avaliadas comparativamente a importância e a satisfação de cada IES pesquisada em relação à gestão dos seus riscos. Os autores concluíram que estudos na área da gestão de riscos aplicada a entidades de ensino são oportunos e proporcionam uma boa área de estudos para as ciências administrativas e contábeis.

Silva (2015) propôs um modelo de gestão de riscos à Universidade Federal do Rio Grande do Norte - UFRN e disponibilizou à gestão da universidade a simulação de um módulo para o seu Sistema de Informação de Gestão - SIPAC, capaz de gerenciar os riscos relativos aos mais variados eventos que podem influenciar no alcance dos objetivos institucionais. $\mathrm{O}$ autor distingue alguns eventos internos e externos que poderiam influenciar no resultado da IFES.

Para Silva (2015), a classificação do risco é definida a partir do produto entre a probabilidade do evento ocorrer e o seu provável impacto. Para isso, foram utilizadas as escalas de 01 a 05 para cada uma das variáveis de risco. O grau de risco, por sua vez, recebia a seguinte classificação: baixo, moderado, alto ou muito alto. A etapa seguinte da pesquisa definiu a resposta ao risco. No questionário, os gestores puderam apresentar as seguintes respostas ao risco: aceitar, mitigar, transferir ou evitar.

Em 2015, a FUB realizou uma avaliação de riscos, tanto no que se refere à gestão de riscos quanto às atividades de controle adotadas para mitigá-los (UnB, 2016a). Para isso, adotou-se a metodologia baseada no Guia de Orientação para Gerenciamento de Riscos do MP (2013). Além disso, foram considerados os riscos apresentados em formulários de outras instituições como a Universidade de Cambridge e a Association of Governing Boards of Universities and Colleges, além dos riscos previamente estabelecidos no PDI (2014-2017) da UnB (2014).

Após a identificação dos riscos, o documento da UnB (2016a) ressaltou a etapa de análise e avaliação. A ferramenta utilizada para a análise e avaliação de riscos foi uma Matriz de Probabilidade e Impacto, permitindo determinar o nível de cada risco a partir da combinação das consequências para a organização (impacto) e a chance de ocorrência (probabilidade). Assim, foi possível conhecer não apenas os fatores que contribuem para a 
ocorrência dos riscos identificados, como também a análise das consequências decorrentes desses riscos (UnB, 2016a).

Brito et al. (2017), como o objetivo de identificar os benefícios e desafios na implantação de uma Auditoria Baseada em Riscos - ABR nas IFES brasileiras constatou que "a gestão de riscos é tema ainda recente no contexto da gestão pública universitária". Sousa et al. (2018), também em uma pesquisa aplicada, comparou as metodologias para gestão de risco desenvolvidas pela Controladoria Geral da União - CGU (2018) e pelo MP (2017) e verificou a possibilidade de adaptação dessas metodologias para a gestão universitária. Os autores concluíram que "é possível a aplicação das metodologias na gestão de riscos das instituições universitárias, contudo, existe a necessidade de adaptação, respeitando as devidas particularidades da gestão universitária".

Devido a importância da gestão de riscos para o bom desempenho dos órgãos/instituições federais públicas, o TCU (2018a), anualmente, obtêm informações sobre os controles da Administração Pública Federal. O tribunal avalia as áreas de pessoas, TI e contratações, destacando que todas as universidades federais brasileiras responderam ao último levantamento e os dados e relatórios gerados são públicos.

\section{PROCEDIMENTOS METODOLOGICOS}

Tal como Pierangeli et al. (2017) e MP (2017), a identificação dos riscos da FUB foi alcançada pela ponderação entre dados referentes ao grau de probabilidade e o grau de impacto do risco. Os dados da probabilidade são secundários e foram obtidos junto ao levantamento do TCU (2018a). Por sua vez, obtiveram-se os dados do impacto por meio da aplicação de questionário aos servidores que exercem função na alta gestão dos decanatos da FUB.

O resultado da multiplicação do grau de probabilidade pelo grau de impacto possibilitou uma análise numérica, permitindo ranquear os riscos entre as seguintes categorias: pequeno, moderado, alto e crítico, conforme metodologia do MP (2017). A opção por utilizar a metodologia empregada pelo MP (2017), bem como os dados do TCU (2018a), além da confiabilidade, teve como intuito alcançar resultados comparáveis e que dialoguem com outras iniciativas de governança na gestão pública que corroboram as referências supracitadas. 


\subsection{DADOS DA PROBABILIDADE DO RISCO}

O TCU enviou questionário com 93 perguntas para os responsáveis pela gestão das empresas públicas, ministérios, tribunais, instituições de ensino, hospitais, dentre outros. Os dados das 488 organizações/instituições que responderam ao questionário estão disponíveis no site do TCU (2018a), sendo utilizados nessa pesquisa apenas os dados da FUB.

O questionário do TCU (2018a) possui cinco séries de perguntas: 1) série 1.000 questões de liderança; 2) série 2.000 - questões de estratégia; 3) série 3.000 - questões de accountability; 4) série 4.100 - questões de pessoal; 5) série 4.200 - questões de TI; e 5) série 4.300 - questões de contratações, (TCU, 2018a). Como o presente trabalho está centrado na gestão de pessoas, utilizou-se apenas os dados das questões da série 4.100 (Quadro 1).

Quadro 1 Questionário relativo à Série 4.100 do Levantamento do TCU

\begin{tabular}{|c|c|}
\hline & \\
\hline 4111 & $\begin{array}{l}\text { A organização define objetivos, indicadores e metas de desempenho para cada função de } \\
\text { gestão de pessoas. }\end{array}$ \\
\hline 4112 & A organização elabora plano(s) específico(s) para orientar a gestão de pessoas. \\
\hline 4113 & organização verifica se os gestores cumprem as políticas de gestão de pessoas. \\
\hline 4121 & $\begin{array}{l}\text { organização define e documenta os perfis profissionais desejados para cada ocupação ou } \\
\text { upo de ocupações de colaboradores. }\end{array}$ \\
\hline 4122 & $\begin{array}{l}\text { organização define e documenta os perfis profissionais desejados para cada ocupação ou } \\
\text { upo de ocupações de gestão. }\end{array}$ \\
\hline 4123 & $\begin{array}{l}\text { organização atualiza, com base em procedimentos técnicos, o quantitativo necessário de } \\
\text { ssoal por unidade organizacional ou por processo de trabalho. }\end{array}$ \\
\hline 4124 & relevantes sobre força de trabalho. \\
\hline 4131 & ados. \\
\hline 4132 & $\begin{array}{l}\text { A organização define os métodos e critérios das seleções externas (p.ex. dos concursos } \\
\text { públicos) com base nos perfis profissionais desejados definidos na prática " } 4120 \text {. Definir } \\
\text { adequadamente, em termos qualitativos e quantitativos, a demanda por colaboradores e } \\
\text { gestores". }\end{array}$ \\
\hline 4133 & $\begin{array}{l}\text { organização estabelece o número de vagas a serem preenchidas nas seleções externas a partir } \\
\text { quantitativo necessário de pessoal por unidade organizacional ou por processo de trabalho, } \\
\text { alizado conforme a prática "4120. Definir adequadamente, em termos qualitativos e } \\
\text { antitativos, a demanda por colaboradores e gestores". }\end{array}$ \\
\hline 4134 & $\begin{array}{l}\text { A organização aloca os colaboradores com base na comparação entre os perfis profissionais } \\
\text { apresentados por eles e os perfis profissionais desejados (documentados) pelas unidades } \\
\text { organizacionais. }\end{array}$ \\
\hline 4141 & nolítion de \\
\hline 4142 & \\
\hline 4143 & A organização elab \\
\hline 4144 & $\begin{array}{l}\text { A organização executa ações educacionais para assegurar a disponibilidade de sucessores } \\
\text { qualificados para as ocupações críticas. }\end{array}$ \\
\hline 4151 & \\
\hline 4152 & ção dos novos colaboradores. \\
\hline 415 & colaboradores que assumem \\
\hline
\end{tabular}




\begin{tabular}{|l|l|}
\hline & \multicolumn{1}{|c|}{ Questões da Série 4100 } \\
\hline 4154 & $\begin{array}{l}\text { A organização avalia as ações educacionais realizadas, com o objetivo de promover melhorias } \\
\text { em ações educacionais futuras. }\end{array}$ \\
\hline 4165 & A organização realiza pesquisas para avaliar o ambiente de trabalho da organização. \\
\hline 4166 & $\begin{array}{l}\text { A organização oferece aos colaboradores condições mais flexíveis e estimulantes para } \\
\text { realização de trabalho, com vistas ao aumento do desempenho. }\end{array}$ \\
\hline 4167 & A organização avalia os resultados obtidos com o programa de qualidade de vida no trabalho. \\
\hline 4171 & $\begin{array}{l}\text { A organização estabelece metas de desempenho individuais e/ou de equipes vinculadas ao } \\
\text { plano da unidade }\end{array}$ \\
\hline 4172 & $\begin{array}{l}\text { A organização realiza formalmente a avaliação de desempenho individual, com atribuição de } \\
\text { nota ou conceito, tendo como critério de avaliação o alcance das metas previstas no plano da } \\
\text { unidade. }\end{array}$ \\
\hline 4173 & $\begin{array}{l}\text { Os avaliadores identificam e documentam as necessidades individuais de capacitação durante o } \\
\text { processo de avaliação de desempenho dos seus subordinados. }\end{array}$ \\
\hline 4174 & $\begin{array}{l}\text { A organização estabelece procedimentos e regras claras e transparentes nas práticas de } \\
\text { reconhecimento. }\end{array}$ \\
\hline 4181 & $\begin{array}{l}\text { A organização executa procedimentos estruturados para aumentar a retenção de colaboradores } \\
\text { e gestores. }\end{array}$ \\
\hline 4182 & $\begin{array}{l}\text { A organização executa procedimentos estruturados para identificar os motivos pessoais dos } \\
\text { desligamentos voluntários da organização. }\end{array}$ \\
\hline 4183 & $\begin{array}{l}\text { A organização executa procedimentos estruturados para identificar os motivos pessoais dos } \\
\text { pedidos de movimentação dos colaboradores dentro da organização. }\end{array}$ \\
\hline
\end{tabular}

Fonte: (TCU, 2018a).

Nota: Excluíram-se as questões afetas a fraude e corrupção por não se relacionarem ao objeto do trabalho.

As questões do Quadro 1 foram mensuradas por meio de uma escala ordinal, onde os respondentes indicaram o grau de adoção de medidas para evitar riscos na gestão de pessoas dentro dos seguintes atributos: "Não se aplica"; "Não adota" e "Há decisão formal ou plano aprovado para adotá-la". Os dados obtidos dessa escala foram transformados pelo TCU (2018a) em valores entre "0" e "1", onde a proximidade do "0" indica baixo grau de adoção de medidas para evitar riscos e a adjacência do "1" indica o oposto, sendo esses dados admitidos nessa pesquisa como uma proxy da probabilidade do risco.

O cálculo da probabilidade " $p$ " ocorreu pela inversão da série, ou seja, o valor obtido junto ao TCU (2018a) foi subtraído por 1 (um), procedimento esse também adotado pelo órgão supracitado. Além disso, conforme a orientação da metodologia do MP (2017), para que a probabilidade possa ser utilizada na construção da matriz de risco é preciso realizar uma outra transformação, ou seja, relacionar o valor da probabilidade (oscilando de 0 a 1) para uma escala que oscile de 1 a 5 . Isto é, se a probabilidade for maior ou igual $90 \%$ ganha peso “5”, se for maior ou igual a $50 \%$ e menor que $90 \%$ ganha peso " 4 ", se a probabilidade for maior ou igual a $30 \%$ e menor que $50 \%$ ganha peso " 3 ", se for maior que $10 \%$ e menor que $30 \%$ ganha peso " 2 "; e se for menor que $10 \%$ ganha peso " 1 ", conforme a Tabela 1. 
Tabela 1 Conversão da Probabilidade em uma Escala de (1-5)

\begin{tabular}{l|c|l}
\hline \multicolumn{1}{c|}{ Escala } & $\begin{array}{c}\text { Frequência } \\
\text { observada/esperada }\end{array}$ & \multicolumn{1}{c}{ Probabilidade } \\
\hline 5- Muito Alta & $(90 \% \geq)$ & $\begin{array}{l}\text { Evento esperado que ocorra na maioria das } \\
\text { circunstâncias }\end{array}$ \\
\hline 4 - Alta & $50 \% \geq \mathrm{e}<90 \%)$ & $\begin{array}{l}\text { Evento provavelmente ocorre na maioria das } \\
\text { circunstâncias }\end{array}$ \\
\hline 3 - Possível & $(30 \% \geq \mathrm{e}<50 \%)$ & Evento deve ocorrer em algum momento \\
\hline 2 - Baixa & $(10 \% \geq \mathrm{e}<30 \%)$ & Evento pode ocorrer em algum momento \\
\hline 1 - Muito Baixa & $(<10 \%)$ & $\begin{array}{l}\text { Evento pode ocorrer apenas em circunstâncias } \\
\text { excepcionais }\end{array}$ \\
\hline
\end{tabular}

Fonte: MP (2017)

\subsection{DADOS DO IMPACTO DO RISCO}

Os dados para mensurar o grau de impacto dos riscos foram obtidos por meio da aplicação questionário para 40 servidores que atuam no topo da gestão de todos os decanatos da FUB. As questões do TCU para mensurar a probabilidade do risco foram adaptadas, mantendo o seu conteúdo, porém formuladas de modo que os entrevistados se posicionassem em uma situação hipotética de ausência de cada item de governança (Quadro 2). O impacto da ausência dos itens de governança foram mensurados em uma escala ordinal de cinco pontos: 1) insignificante; 2) pequeno; 3) moderado; 4) grande e 5) catastrófico. Os dados foram coletados entre os meses de março e maio de 2019.

Quadro 2 Questionário relativo à Série 4.100 para mensurar o impacto dos riscos

\begin{tabular}{|c|l|}
\hline 4111 & $\begin{array}{l}|c| \\
\text { Sdaptação das Questões da Série 4100 } \\
\text { de pessoas, o impacto poderá ser: }\end{array}$ \\
\hline 4112 & $\begin{array}{l}\text { Se não houver a elaboração de plano(s) específico(s) para orientar a gestão de pessoas, o } \\
\text { impacto poderá ser: }\end{array}$ \\
\hline 4113 & $\begin{array}{l}\text { Caso não se verifique se os gestores cumprem as políticas de gestão de pessoas, o impacto } \\
\text { poderá ser: }\end{array}$ \\
\hline 4121 & $\begin{array}{l}\text { Se não for definido e documentado os perfis profissionais desejados para cada ocupação ou } \\
\text { grupo de ocupações de colaboradores, o impacto poderá ser: }\end{array}$ \\
\hline 4122 & $\begin{array}{l}\text { Se não for definido e documentado os perfis profissionais desejados para cada ocupação ou } \\
\text { grupo de ocupações de gestão, o impacto poderá ser: }\end{array}$ \\
\hline 4123 & $\begin{array}{l}\text { Caso não haja atualização, com base em procedimentos técnicos, do quantitativo necessário de } \\
\text { pessoal por unidade organizacional ou por processo de trabalho, o impacto poderá ser: }\end{array}$ \\
\hline 4124 & $\begin{array}{l}\text { Sem o monitoramento do conjunto de indicadores relevantes sobre força de trabalho, o impacto } \\
\text { poderá ser: }\end{array}$ \\
\hline 4131 & $\begin{array}{l}\text { Se a escolha de gestores não for realizada segundo perfis profissionais definidos e } \\
\text { documentados, o impacto poderá ser: }\end{array}$ \\
\hline 4132 & $\begin{array}{l}\text { Se não houver definição de métodos e critérios para as seleções externas (p.ex. dos concursos } \\
\text { públicos) com base nos perfis profissionais desejados definidos, o impacto poderá ser: }\end{array}$ \\
\hline
\end{tabular}




\section{GESTÃO DE RISCOS NA ÁREA DE PESSOAL À LUZ DA EMENDA CONSTITUCIONAL 95/2016: UMA APLICAÇÃO PARA A UNIVERSIDADE DE BRASÍLIA \\ DOI: http://dx.doi.org/10.5007/1983-4535.2020v13n3p232}

\begin{tabular}{|c|c|}
\hline & Adaptação das Questões da Série 4100 \\
\hline 4133 & $\begin{array}{l}\text { Caso não seja estabelecido o número de vagas a serem preenchidas nas seleções externas a } \\
\text { partir do quantitativo necessário de pessoal por unidade organizacional ou por processo de } \\
\text { trabalho, o impacto poderá ser: }\end{array}$ \\
\hline 4134 & $\begin{array}{l}\text { Se a alocação dos colaboradores não for feita com base na comparação entre os perfis } \\
\text { profissionais apresentados por eles e os perfis profissionais desejados (documentados) pelas } \\
\text { unidades organizacionais, o impacto poderá ser: }\end{array}$ \\
\hline 4141 & Caso uma política de sucessão não seja colocada à disposição, o impacto poderá ser: \\
\hline 4142 & Se não ocorrer a identificação de quais são as suas ocupações críticas, o impacto poderá ser: \\
\hline 4143 & Se não for executado um plano de sucessão para as ocupações críticas, o impacto poderá ser: \\
\hline 4144 & $\begin{array}{l}\text { Caso não sejam executadas ações educacionais para assegurar a disponibilidade de sucessores } \\
\text { qualificados para as ocupações críticas, o impacto poderá ser: }\end{array}$ \\
\hline 4151 & $\begin{array}{l}\text { Sem que ocorra a identificação e a documentação de lacunas de competência da organização, o } \\
\text { impacto poderá ser: }\end{array}$ \\
\hline 4152 & $\begin{array}{l}\text { Caso não sejam executadas ações educacionais específicas para formação dos novos } \\
\text { colaboradores, o impacto poderá ser: }\end{array}$ \\
\hline 4153 & $\begin{array}{l}\text { Se não forem ofertadas ações de desenvolvimento de liderança aos colaboradores que assumem } \\
\text { funções gerenciais, o impacto poderá ser: }\end{array}$ \\
\hline 4154 & $\begin{array}{l}\text { So não ocorra avaliação das ações educacionais realizadas, com o objetivo de promover } \\
\text { lhorias em ações educacionais futuras, o impacto poderá ser: }\end{array}$ \\
\hline 4165 & $\begin{array}{l}\text { Se não realizarem pesquisas para avaliar o ambiente de trabalho da organização, o impacto } \\
\text { poderá ser: }\end{array}$ \\
\hline 4166 & $\begin{array}{l}\text { Se não for ofertado aos colaboradores condições mais flexíveis e estimulantes para realização } \\
\text { de trabalho, com vistas ao aumento do desempenho, o impacto poderá ser: }\end{array}$ \\
\hline 4167 & $\begin{array}{l}\text { Caso não sejam avaliados os resultados obtidos com o programa de qualidade de vida no } \\
\text { trabalho, o impacto poderá ser: }\end{array}$ \\
\hline 4171 & $\begin{array}{l}\text { Se não forem estabelecidas metas de desempenho individuais e/ou de equipes vinculadas ao } \\
\text { plano da unidade, o impacto poderá ser: }\end{array}$ \\
\hline 4172 & $\begin{array}{l}\text { Se não for realizada avaliação formal de desempenho individual, com atribuição de nota ou } \\
\text { conceito, tendo como critério de avaliação o alcance das metas previstas no plano da unidade, o } \\
\text { impacto poderá ser: }\end{array}$ \\
\hline 4173 & $\begin{array}{l}\text { Caso não seja feita a identificação e documentação das necessidades individuais de capacitação } \\
\text { durante o processo de avaliação de desempenho dos seus subordinados, o impacto poderá ser: }\end{array}$ \\
\hline 4174 & $\begin{array}{l}\text { Se não existirem o estabelecimento de procedimentos e regras claras e transparentes nas práticas } \\
\text { de reconhecimento, o impacto poderá ser: }\end{array}$ \\
\hline 4181 & $\begin{array}{l}\text { Se não forem executados procedimentos estruturados para aumentar a retenção de } \\
\text { colaboradores e gestores, o impacto poderá ser: }\end{array}$ \\
\hline 4182 & $\begin{array}{l}\text { Caso não haja a execução de procedimentos estruturados para identificar os motivos pessoais } \\
\text { dos desligamentos voluntários da organização, o impacto poderá ser: }\end{array}$ \\
\hline 4183 & $\begin{array}{l}\text { Se não houver a execução de procedimentos estruturados para identificar os motivos pessoais } \\
\text { dos pedidos de movimentação dos colaboradores dentro da organização, o impacto poderá ser: }\end{array}$ \\
\hline
\end{tabular}

Fonte: (TCU, 2018a).

Nota: Excluíram-se as questões afetas a fraude e corrupção por não se relacionarem ao objeto do trabalho.

\subsection{IDENTIFICAÇÃO DOS RISCOS CRÍTICOS DA ÁREA DE PESSOAL DA FUB}

A obtenção do nível de risco ocorreu pela multiplicação da medida de probabilidade pelos valores referentes ao grau de impacto. Amparado em Sousa et al. (2018), o resultado 
desse produto é interpretado conforme a Matriz de Risco estabelecida pelo MP (2017) (Figura 1).

Figura 1 Matriz de Risco proposta pelo MP (2017)

\begin{tabular}{|c|c|c|c|c|c|}
\hline \multirow[b]{3}{*}{ 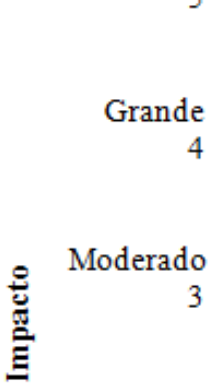 } & $\begin{array}{c}5 \\
\text { Risco } \\
\text { Moderado }\end{array}$ & $\begin{array}{c}10 \\
\text { Risco Alto }\end{array}$ & $\begin{array}{c}15 \\
\text { Risco } \\
\text { Crítico }\end{array}$ & $\begin{array}{c}20 \\
\text { Risco } \\
\text { Crítico }\end{array}$ & $\begin{array}{c}25 \\
\text { Risco } \\
\text { Crítico }\end{array}$ \\
\hline & $\begin{array}{c}4 \\
\text { Risco } \\
\text { Moderado } \\
\end{array}$ & $\begin{array}{c}8 \\
\text { Risco Alto }\end{array}$ & $\begin{array}{c}12 \\
\text { Risco Alto }\end{array}$ & $\begin{array}{c}16 \\
\text { Risco } \\
\text { Crítico }\end{array}$ & $\begin{array}{c}20 \\
\text { Risco } \\
\text { Crítico }\end{array}$ \\
\hline & $\begin{array}{c}3 \\
\text { Risco } \\
\text { Pequeno }\end{array}$ & $\begin{array}{c}6 \\
\text { Risco } \\
\text { Moderado } \\
\end{array}$ & $\begin{array}{c}9 \\
\text { Risco Alto }\end{array}$ & $\begin{array}{c}12 \\
\text { Risco Alto }\end{array}$ & $\begin{array}{c}15 \\
\text { Risco } \\
\text { Crítico }\end{array}$ \\
\hline $\begin{array}{r}\text { Pequeno } \\
2\end{array}$ & $\begin{array}{c}2 \\
\text { Risco } \\
\text { Pequeno }\end{array}$ & $\begin{array}{c}4 \\
\text { Risco } \\
\text { Moderado } \\
\end{array}$ & $\begin{array}{c}6 \\
\text { Risco } \\
\text { Moderado } \\
\end{array}$ & $\begin{array}{c}8 \\
\text { Risco Alto }\end{array}$ & $\begin{array}{c}10 \\
\text { Risco Alto }\end{array}$ \\
\hline \multirow{2}{*}{$\begin{array}{r}\text { Insignificante } \\
1\end{array}$} & $\begin{array}{c}1 \\
\text { Risco } \\
\text { Pequeno }\end{array}$ & $\begin{array}{c}2 \\
\text { Risco } \\
\text { Pequeno }\end{array}$ & $\begin{array}{c}3 \\
\text { Risco Pequeno }\end{array}$ & $\begin{array}{c}4 \\
\text { Risco } \\
\text { Moderado }\end{array}$ & $\begin{array}{c}5 \\
\text { Risco } \\
\text { Moderado }\end{array}$ \\
\hline & $\begin{array}{c}1 \\
\text { Muito baixa }\end{array}$ & $\begin{array}{c}2 \\
\text { Baixa }\end{array}$ & $\begin{array}{c}3 \\
\text { Possível } \\
\text { Probabilidade }\end{array}$ & $\begin{array}{c}4 \\
\text { Alta }\end{array}$ & $\begin{array}{c}5 \\
\text { Muito alta }\end{array}$ \\
\hline
\end{tabular}

Fonte: MP (2017).

Dentre as limitações da utilização da proxy de probabilidade, cabe ressaltar que não é possível afirmar com $100 \%$ de certeza que ao se deixar de realizar integralmente alguma medida de governança o evento negativo ocorrerá com absoluta certeza. Isso ocorre porque outras medidas de governança que estejam sendo tomadas poderão ajudar a mitigar esse risco. Limitação similar a que foi admitida pelo TCU (2018) em trabalho que mapeou a exposição a fraude e corrupção na administração pública.

Outro aspecto a se destacar é que os riscos identificados na presente pesquisa, e que contaram com dados do questionário do TCU (2018a), não representam todos os riscos da área de pessoal da FUB. A metodologia aplicada pelo levantamento do TCU (2018a) consolida procedimentos de governança e gestão usualmente empregados nas organizações, mas não tem a intenção de avaliar todos os riscos possíveis da administração pública. 


\section{RESULTADOS E DISCUSSÕES}

Os resultados foram enquadrados em uma matriz de risco para a área de pessoal da FUB que classificou os 29 riscos analisados entre os níveis: crítico, alto e moderado (Quadro $3)$.

Quadro 3 Nível de Risco da Ausência ou Deficiência nos Controles

\begin{tabular}{|c|c|}
\hline $\begin{array}{l}\text { Nível de } \\
\text { risco }\end{array}$ & Variável \\
\hline \multirow{19}{*}{ Crítico } & $\begin{array}{l}\text { Indefinição de objetivos, indicadores e metas de desempenho para cada função de } \\
\text { gestão de pessoas. }\end{array}$ \\
\hline & Não cumprimento das políticas de gestão de pessoas. \\
\hline & $\begin{array}{l}\text { Indefinição dos perfis profissionais desejados para cada ocupação ou grupo de } \\
\text { ocunacões de colaboradores. }\end{array}$ \\
\hline & $\begin{array}{l}\text { Indefinição dos perfis profissionais desejados para cada ocupação ou grupo de } \\
\text { ocupaçôes de gestão. }\end{array}$ \\
\hline & $\begin{array}{l}\text { Não atualização do quantitativo necessário de pessoal por unidade organizacional ou } \\
\text { por processo de trabalho. }\end{array}$ \\
\hline & Falta de monitoramento do conjunto de indicadores relevantes sobre força de trabalho. \\
\hline & Escolha de gestores sem seguir perfis profissionais definidos e documentados. \\
\hline & $\begin{array}{l}\text { Alocação indevida dos colaboradores sem ser feita com base na comparação entre os } \\
\text { perfis profissionais apresentados por eles e os perfis profissionais desejados } \\
\text { (documentados) pelas unidades organizacionais. }\end{array}$ \\
\hline & Falta de uma política de sucessão. \\
\hline & Falta de identificação de quais são as suas ocupações críticas. \\
\hline & Falta de execução de um plano de sucessão para as ocupações críticas. \\
\hline & $\begin{array}{l}\text { Falta de execução de ações educacionais para assegurar a disponibilidade de sucessores } \\
\text { qualificados para as ocupações críticas. }\end{array}$ \\
\hline & Falta de identificação de lacunas de competência da organização. \\
\hline & Inexistência de ações educacionais específicas para formação dos novos colaboradores. \\
\hline & $\begin{array}{l}\text { Falta de condições mais flexíveis e estimulantes para realização de trabalho, com vistas } \\
\text { ao aumento do desempenho. }\end{array}$ \\
\hline & $\begin{array}{l}\text { Falta de avaliação dos resultados obtidos com o programa de qualidade de vida no } \\
\text { trabalho. }\end{array}$ \\
\hline & $\begin{array}{l}\text { Falta de procedimentos estruturados para aumentar a retenção de colaboradores e } \\
\text { gestores. }\end{array}$ \\
\hline & $\begin{array}{l}\text { Não execução de procedimentos estruturados para identificar os motivos pessoais dos } \\
\text { desligamentos voluntários da organização. }\end{array}$ \\
\hline & $\begin{array}{l}\text { Não execução de procedimentos estruturados para identificar os motivos pessoais dos } \\
\text { pedidos de movimentação dos colaboradores dentro da organização. }\end{array}$ \\
\hline \multirow{4}{*}{ Alto } & $\begin{array}{l}\text { Falta de avaliação das ações educacionais realizadas, com o objetivo de promover } \\
\text { melhorias em ações educacionais futuras. }\end{array}$ \\
\hline & Não realização de pesquisas para avaliar o ambiente de trabalho da organização. \\
\hline & $\begin{array}{l}\text { Falta de estabelecimento de metas de desempenho individuais e/ou de equipes } \\
\text { vinculadas ao plano da unidade. }\end{array}$ \\
\hline & $\begin{array}{l}\text { Falta de avaliação formal de desempenho individual, com atribuição de nota ou } \\
\text { conceito, tendo como critério de avaliação o alcance das metas previstas no plano da } \\
\text { unidade. }\end{array}$ \\
\hline
\end{tabular}




\begin{tabular}{|l|l|}
\hline \multirow{7}{*}{ Moderado } & $\begin{array}{l}\text { Não identificação e documentação das necessidades individuais de capacitação durante } \\
\text { o processo de avaliação de desempenho dos seus subordinados. }\end{array}$ \\
\cline { 2 - 3 } & $\begin{array}{l}\text { Falta estabelecimento de procedimentos e regras claras e transparentes nas práticas de } \\
\text { reconhecimento. }\end{array}$ \\
\hline & $\begin{array}{l}\text { Falta elaboração de plano(s) específico(s) para orientar a gestão de pessoas. } \\
\text { Falta definição de métodos e critérios para as seleções externas (p.ex. dos concursos } \\
\text { públicos) com base nos perfis profissionaio de procedimento para que a FUB estabeleça o número de vagas a serem } \\
\text { unidade organizacional ou por processo de trabalho. }\end{array}$ \\
\cline { 2 - 3 } & $\begin{array}{l}\text { Inexistência de ações de desenvolvimento de liderança aos colaboradores que assumem } \\
\text { funções gerenciais. }\end{array}$ \\
\hline
\end{tabular}

$\mathrm{Na}$ análise de riscos realizada para a FUB foram identificados 19 riscos em nível crítico (65\%), seis em nível alto (21\%), quatro em nível moderado (14\%), sendo que nenhum risco fora considerado como pequeno. Cabe destacar que, segundo De Cicco (2018), todos os riscos devem ser atacados pelas organizações, devendo ser priorizados aqueles que tenham maior potencial de prejuízo, cabendo, portanto, à FUB criar planos de ações para mitigá-los.

Em relação aos riscos críticos e resumindo os resultados do Quadro 3, verificou-se que os mesmos se concentram em dois aspectos: 1) falhas na definição da força de trabalho necessária nas unidades e 2) falhas na identificação dos perfis dos servidores (colaboradores e gestores) que seriam necessários nessas áreas. Conforme as respostas apresentadas em TCU (2018a), a FUB declara não monitorar adequadamente os indicadores sobre sua força de trabalho, ou seja, não sabe o quantitativo necessário em cada unidade, nem tão pouco as aposentadorias que podem vir a ocorrer.

Identificou-se que as deficiências na definição da demanda e dos perfis de colaboradores e gestores gera desperdício de recursos, haja vista que a contratação de pessoal pode vir a ocorrer sem a real necessidade ou sem o perfil profissional que a organização precisa. Isto é, a tomada de decisão pode estar sendo inadequada em relação à seleção/contratação de novos colaboradores, bem como a alocação dos já existentes, devido à falta de informações objetivas e precisas sobre a real situação da força de trabalho da FUB.

Segundo TCU (2018a), a ausência de procedimentos que mitiguem os riscos críticos identificados gera evidências de que a estratégia organizacional e o conjunto de políticas e práticas de gestão de pessoas estejam desalinhadas na FUB, ou seja, é possível que projetos, políticas e práticas aconteçam sem o direcionamento de uma visão estratégica. As deficiências identificadas na FUB aumentam o risco de que competências necessárias para a consecução 
da estratégia organizacional não sejam desenvolvidas tempestivamente e que se perca conhecimento por conta da falta de uma política de retenção de conhecimentos.

Os riscos classificados como altos, por sua vez, representaram $21 \%$ do total e se concentraram em deficiências de gestão. Isto é, identificou-se que a principal causa dessa falha de gestão se relacionou com o fato da instituição não definir metas individuais para seus colaboradores e não realizar avaliação de desempenho para verificar atingimento de metas. Esses resultados podem ser corroborados pelo Relatório de Gestão do Decanato de Gestão de Pessoas (UnB, 2016b), sendo apontando que a FUB só realiza avaliação de desempenho para os servidores em estágio probatório, isto é, aproximadamente $20 \%$ da sua força de trabalho (UnB, 2016b).

Segundo TCU (2018a), a organização que não avalia os servidores, não identifica lacunas de competências para direcionar a capacitação e tão pouco consegue realizar políticas para incentivar o incremento de produtividade, o nível de satisfação e a realização com o trabalho.

Os 19 riscos críticos e os seis riscos altos, ou seja, $86 \%$ de todos os riscos analisados, já são suficientes para concluir que a FUB não está suficientemente preparada para o cenário de restrição de contratação da força de trabalho que será imposto pela EC 95/2016. Isto é, os resultados permitem inferir riscos preocupantes de continuidade ou de perda da qualidade da entrega de algumas áreas e de serviços da FUB.

Apenas quatro riscos foram considerados moderados, estando concentrados nos processos de seleção externa e na existência de planos de gestão de pessoal, podendo ser interpretados como os menos preocupantes, relativamente. Esses riscos foram considerados moderados, provavelmente, por que a percepção é de que a UnB possui planos e procedimentos definidos, o problema é a qualidade e a implementação dos mesmos.

Os agrupamentos citados nos parágrafos anteriores evidenciam que os riscos interagem entre si. Assim, o planejamento estratégico para atender à demanda se relaciona com o perfil do servidor a ser demandado, orientando a política de recrutamento. Já a capacitação orienta-se pelas: 1) competências necessárias para atingir as finalidades da instituição, 2) ações de preparação dos sucessores, 3) políticas de retenção do conhecimento e de criação de um ambiente favorável, todas essas, fundamentais para gestão do conhecimento e para continuidade das atividades da FUB. 
Um estudo que corrobora com os resultados encontrados foi realizado pela própria UnB (2016a), essa pesquisa ressaltou os seguintes pontos de risco: de gestão de pessoas, de alta rotatividade de servidores (saída para outros órgãos), de inexistência de plano de carreira atrativo, de restrições orçamentárias, e de reduzida capacidade de atrair e manter servidores. Na mesma linha, os resultados de Brito et al. (2017, p. 123) quanto a implantação de gestão de riscos em todas as IFES foram:

A grande maioria dos respondentes $(73,23 \%)$ afirmou que ainda não foi implantada gestão de riscos na instituição, enquanto $14,96 \%$ apontam que a implantação ocorreu há menos de 1 ano. Apenas 8,66\% dos respondentes afirmam que a implantação da gestão de riscos na instituição ocorreu há mais de 1 ano (Brito et al. 2017, p. 123)

A FUB identificou que o Decanato de Gestão de Pessoas - DGP contava em 2016 com um único Sistema de Pessoal - SIPES desenvolvido na década de 1980 e que não trazia todas as ferramentas necessárias para controle de informações (UnB, 2016a). Além disso, cita o estudo que existia o risco de mapeamento ineficaz de processos de trabalho que tinham elevado impacto na qualidade dos serviços que a instituição oferecia.

Os resultados da UnB (2016a) encontraram-se igualmente alinhados aos de Correio e Correio (2019) e de Brito et al. (2017). Em geral, ambas as referências buscaram investigar as práticas de governança pública empregadas pelos órgãos da Administração Pública Federal Brasileira e concluíram que, dentre as práticas de governança, aquelas relacionadas a gestão de riscos estão entre as menos adotadas.

Em relação ao gerenciamento de todos os riscos citados acima, De Cicco (2018) menciona que as opções de tratamento de riscos não são mutuamente exclusivas ou adequadas em todas as circunstâncias. Conforme o autor, as opções podem incluir os seguintes aspectos: 1) ação de evitar o risco ao se decidir não iniciar ou descontinuar a atividade que lhe dá origem; 2) tomada ou aumento do risco na tentativa de tirar proveito de uma oportunidade; 3 ) remoção da fonte de risco; 4) alteração da probabilidade; 5) alterações das consequências; 6) compartilhamento do risco com outras partes e 7) retenção do risco por uma decisão consciente e bem embasada.

Além disso, De Cicco (2018) cita que o monitoramento merece ser planejado como parte do processo de gestão de riscos e envolve a checagem ou vigilância regulares e que as responsabilidades necessitam estar claramente definidas na organização. Alinhado a De Cicco 
(2018),a Azevedo et al. (2017) destacou vários benefícios do compliance (agir de acordo uma regra) para a gestão de riscos nos processos organizacionais.

Em suma, apesar da análise de risco da FUB identificar que existem muitos riscos a serem tratados e mitigados, observou-se que a fundação não se encontra muito distante da realidade de outros órgãos/instituições da administração pública do Brasil. Segundo Levantamento de Governança do TCU (2018a), embora as necessidades das Unidades e Gestão de Pessoal ultrapassem o simples cumprimento de normas, a gestão de pessoas no âmbito federal tende a permanecer limitada a questões normativas. Esse quadro contrasta com o que se entende modernamente do assunto, uma vez que as pessoas compõem o fator crítico e essa área deve, portanto, ser gerida de forma estratégica.

Ao levantar a situação na administração pública federal, o TCU (2018a) encontrou a maior parte das organizações ainda limitadas ao mero cumprimento das leis, normas e regulamentos, isto é, sem realizar uma Gestão Estratégica de Pessoal. Ainda segundo o TCU (2018a), 58\% das 488 organizações investigadas não têm um planejamento de pessoal estruturado. Uma das consequências da falta de planejamento na gestão de pessoas é o prejuízo na capacidade da organização estimar suas necessidades de recursos humanos e quantificar demandas por novos colaboradores, informações básicas para processos seletivos. Além disso, 56\% das organizações apresentaram um nível de governança de pessoal inexistente e/ou inicial.

O TCU (2018a) ressalta a necessidade da Administração Pública Federal fortalecer suas Unidades de Gestão de Pessoal para que estas possam atuar de forma estratégica nos seus recursos humanos. Nessa esteira, Meneses et al. (2012) identificaram o perfil de atuação vigente nas Unidades de Gestão de Pessoas - UGPs de órgãos setoriais da administração pública direta. Segundo esses autores, predominam-se o perfil tradicional e burocrático nas UGPs. Tal conclusão é embasada em resultados que mostraram uma forte centralização administrativa, uma orientação para o controle operacional e uma aderência irrestrita às normas. A pesquisa também destacou que aspectos apontados na literatura como estratégicos não se sobressaíram ao modelo burocrático vigente.

Pantoja e Ribeiro (2012) ao avaliarem se as UGPs monitoraram um núcleo de informações relevantes para a organização e se as UGPs realizam e ou participam de um processo de planejamento da força de trabalho, concluíram que ainda existe significativa necessidade de fortalecer a capacidade de gestão das UGPs, no que diz respeito ao 
planejamento da força de trabalho e na definição de perfis de competências profissionais e gerenciamento de informações.

Reforçando a importância da necessidade do fortalecimento das UGPs o DGP da FUB afirma em seu Relatório de Gestão de 2016 que carece de ampla modernização administrativa, com pelo menos quatro componentes: 1) mapeamento de processos; 2) descentralização de processos; 3) implantação de sistema integrado de controle administrativo, articulado com outros sistemas em outros decanatos; e 4) treinamento em competências específicas. Pois, segundo esse relatório, identificaram-se casos de: lacunas de competência e também de conflito de competências; procedimentos com centralização exagerada, excedendo os controles demandados por legislação específica; condição de trabalho fragilizada dos servidores, comprometendo o bom atendimento ao público; alta rotatividade de servidores dificultando o treinamento adequado das equipes de trabalho (UnB, 2016b).

Os resultados do relatório da UnB (2016b) corroboram a visão de Schikmann (2010) ao identificar características negativas ainda encontradas nas organizações da administração pública brasileira como: a rigidez imposta pela legislação; a desvinculação da visão do cidadão como destinatário dos serviços; a pouca ênfase no desempenho; os limites à postura inovativa; os poucos mecanismos de planejamento e a pouca preocupação com a gestão. Nas áreas de pessoal - à semelhança do perfil dos tradicionais departamentos de pessoal - o autor supracitado apontou como frequente as seguintes características: estruturação segundo procedimentos (folha de pagamento, benefícios, legislação e ações pontuais); atuação reativa; foco em questões emergenciais; falta de visão sistêmica; falta de alinhamento entre estrutura de cargos, falta de demandas multifuncionais e de orientação para o desempenho.

Nessa linha, Selden (2010), ressalta que algumas reformas nas áreas de recursos humanos nos últimos anos têm sido impulsionadas por motivos políticos, administrativos e técnicos, em alguns casos, transformaram a gestão de recursos humanos no setor público de regulatória e reativa em estratégica e proativa. Portanto, entende-se que a EC 95/2016, em última análise, pode ser vista como uma oportunidade para que as UGPs das IFES sejam fortalecidas e que passem a realizar uma abordagem estratégica, de natureza sistêmica, voltada para a gestão do capital humano, de forma planejada, integrada à estratégia organizacional e às contingências ambientais com foco na sobrevivência e competitividade organizacional no curto e no longo prazo. A íntima relação entre o risco de uma mudança com 
a oportunidade de melhoria é constatada no trabalho de Peleias et al. (2017), ainda que em uma dinâmica para empresas privadas, onde é normal as crises criarem oportunidades.

A administração pública federal, inclusive a FUB, precisariam migrar efetivamente para um modelo de gestão estratégica de pessoal, que por meio de uma UGP atuante realizaria a mobilização do capital humano para a consecução de estratégias de longo prazo, sendo que suas políticas visariam uma cultura de desenvolvimento contínuo, promovendo maior versatilidade, amplitude e aplicação de conhecimentos e habilidades dos indivíduos (Meneses et al., 2012).

Segundo Snell (1998), as ações voltadas à gestão estratégica dos recursos humanos resultariam na maior capacidade adaptativa da organização a mudanças do ambiente, maior competitividade e capacidade de sobrevivência no longo prazo. Dentre as várias iniciativas com o foco estratégico, a terceirização poderia ser uma delas, desde que os valores públicos não sejam perdidos, conforme destacado na pesquisa de Santos et al. (2019), bem como a adoção de outros instrumentos para a gestão de recursos humanos como, por exemplo, a admissão de remuneração variável como forma de incentivo ao desempenho do servidor público, instrumento esse avaliado no trabalho de Guimarães e Marconi (2017).

Por fim, dada a necessidade de se iniciar a mudança da postura de gestão de risco da FUB, é importante ressaltar a criação pelo Conselho de Administração da instituição em 2019, por meio da Resolução 0004/2019, do Comitê de Governança, Riscos, Controles e Integridade e da Política de Gestão de Riscos (UnB, 2019). Essa política tem a finalidade de promover: a sistematização da gestão de riscos como processo institucional contínuo e interativo; o estabelecimento de níveis adequados de exposição a riscos, de forma a contribuir para a consecução dos objetivos institucionais; a melhoria contínua dos processos de tomada de decisão, com o objetivo de assegurar o acesso tempestivo a informações quanto aos riscos aos quais a FUB está exposta. Destaca-se a importância dessa iniciativa, contudo, espera-se que esse Comitê não se resuma a criação de planos e procedimentos genéricos ou pouco aplicados, e que seja engajado na implementação, monitoramento de resultados e em uma gestão focada na melhoria contínua.

\section{CONSIDERAÇÕES FINAIS}

Para se avaliar os riscos na gestão de pessoal da FUB, fez-se necessário entender o contexto interno e externo que pode afetar essa análise. Em relação ao contexto externo, 
destaca-se a promulgação da EC 95/2016. Esta emenda criou um novo regime fiscal e um teto nos gastos públicos para evitar que as despesas cresçam mais que a inflação.

Nesse cenário, verificou-se alguns fatos críticos relacionado à FUB: 1) a Universidade já gasta aproximadamente $84 \%$ de seu orçamento com despesas de pessoal (ativos, inativos e encargos), ou seja, não existe margem para aumentar esse gasto sem comprometer as outras despesas correntes (luz, água e manutenção) e os investimentos; 2) a faixa etária dos servidores indica que muitos já possuem tempo suficiente para aposentar, isto é, podem se retirar a qualquer momento ou em um futuro próximo; 3) por conta da EC 95/2016 é de se esperar que os órgãos não logrem preencher as vagas dos servidores aposentados, haja vista que o limite de gastos dos órgãos continuam comprometidos com as aposentadorias, o que pode gerar um risco de descontinuidade de algumas atividades da FUB.

A pesquisa logrou desenvolver uma sistemática que permitiu analisar o nível de gerenciamento de risco de pessoal da FUB, na medida em que identificou e categorizou os riscos críticos de sua área de pessoal. Ao se combinar a metodologia de riscos do MP (2017) e as bases de dados do TCU (2018a) gerou-se uma sistemática útil à identificação, análise e priorização dos riscos críticos.

Observou-se que de um total de 29 questões existiam 19 riscos críticos e seis altos, representando quase $90 \%$ de todas as questões avaliadas. Tais riscos se relacionam com o fato da FUB apresentar falhas: na definição da força de trabalho necessária nas unidades; na identificação dos perfis dos servidores (colaboradores e gestores) que seriam necessários nessas áreas; e na gestão (não definir metas individuais para seus colaboradores e não realizar avaliação de desempenho). O que demonstra, em última instância, um baixo nível de gestão de riscos de pessoal na FUB.

Em suma, conclui-se que a FUB não está suficientemente preparada, em relação à gestão de pessoas, para fazer frente aos riscos impostos pela diminuição da força de trabalho futura, pelas aposentadorias e pela dificuldade de reposição gerada pela EC 95/2016. Como consequência da ausência de gestão de riscos na área de pessoal espera-se desses possíveis efeitos: alta rotatividade dos servidores; não desenvolvimento de competências necessárias para a consecução da estratégia organizacional; descontinuidade da administração graças à baixa capacidade de retenção de conhecimento; e a descontinuidade e redução da qualidade das entregas da FUB, gerando desperdício de recursos com a contratação de pessoal sem a real necessidade ou sem o perfil profissional que a organização precisará no presente e no 
futuro; risco de que projetos, políticas e práticas estejam acontecendo sem o direcionamento de uma visão estratégica, dentre outros.

O cenário futuro não se aparenta promissor, exceto pela criação do Comitê de Governança, Riscos, Controles e Integridade e do estabelecimento da Política de Gestão de Riscos em 2019, iniciativas recentes e que ainda não mostraram sua efetividade.

Apesar da metodologia aplicada não permitir uma extrapolação direta dos resultados da FUB para outras IFES, entende-se que a aplicação da metodologia per si é totalmente aplicável a qualquer outra universidade federal, haja vista que os dados obtidos (direta e indiretamente) e o cenário externo são bastante similares em todas as universidades federais.

\section{REFERÊNCIAS}

ÁVILA, M. D. G. Gestão de Riscos no Setor Público. Revista Controle, v. 12, n. 2, p. 179 $198,2014$.

AZEVEDO, M. M. DE; CARDOSO, A. A.; DARTE, J. G.; FEDERICO, B. E.; LIMA, M. A. F. O compliance e a gestão de riscos nos processos organizacionais. Revista de PósGraduação Multidisciplinar, v. 1, n. 1, p. 179-196, 2017.

BRASIL. Emenda Constitucional no 95, de 15 de dezembro de 2016. Altera o ato das disposições constitucionais transitórias, para instituir o novo regime fiscal, e dá outras providências. Diário Oficial da União, Brasília, v. 153, n. 240, p. 2, 16 dez. Seção 1, 2016.

BRITO, G. C. de; PIMENTA, D. P.; SOUZA, E. M. S. de; CRUZ, A. F. da. Benefícios e desafios na implantação da auditoria baseada em risco em Instituições Federais de Ensino. Revista Gestão Universitária na America Latina - GUAL, v. 10, n. 4, p. 109 - 133, 2017. CGU. Ministério da Transparência e Controladoria Geral da União. Metodologia de Gestão de Riscos. Brasília, 2018.

CORREIO, M. N. O. P.; CORREIO, O. V. de O. Práticas de Governança Pública Adotadas pela Administração Pública Federal Brasileira. Administração Pública e Gestão Social, v. 11, n. 2, p. 1 - 16, 2019.

MP. Ministério do Planejamento, Desenvolvimento e Gestão. Projeto de Desenvolvimento do Guia de Orientação para o Gerenciamento de Riscos. Produto VII: Guia de Orientação para o Gerenciamento de Riscos, 2013.

MP. Ministério do Planejamento, Orçamento e Gestão. Matriz de Riscos - Gestão de Integridade, Riscos e Controles Internos da Gestão, 2017.

CHING, H. Y.; COLOMBO, T. M. Boas práticas de Gestão de Risco Corporativo: Estudo de Dez Empresas. Revista Brasileira de Estratégia, v. 5, n. 1, p. 23 - 35, 2013. 
DE CICCO, F. Gestão de riscos - Diretrizes para a implementação da ISO 31000:2018. Coleção Risk Technology, 2018.

DIONNE, G. Risk management: history, definition, and critique. Risk Management and Insurance Review, v. 16, n. 2, p. 147- 166, 2013.

IIA. Institute of Internal Auditors. Controle Interno - Estrutura Integrada, 2013.

Disponível em: <http://www.auditoria.mpu.mp.br/bases/legislacao/COSO-I-

ICIF_2013_Sumario_Executivo.pdf>. Acesso em 20 de maio de 2019.

ISO 31.000. International Organization for Standardization. Risk Management System Principles and Guidelines. Associação Brasileira de Normas Técnicas (ABNT) Projeto 63:000.01- 001, 2009.

MENESES . P . P . M.; PASCHOAL, T.; FONSECA, D.; REIS, M.; GOMES, N.;

GUEVARA, I.; ISIDRO FILHO, A. Mapeamento do Perfil Funcional das Unidades de Gestão de Pessoas em Órgãos Setoriais da Administração pública. V Congresso CONSAD de Gestão Pública. Anais... Brasília - DF, 2012.

GUIMARÃES, S. C.; MARCONI, N. O Impacto da Remuneração Variável no Desempenho do Servidor Público. Administração Pública e Gestão Social, v. 9, n. 1, p. 43 - 53, 2017.

PANTOJA, M. J.; RIBEIRO, S. M. R. Caracterização do perfil e análise da capacidade operacional das unidades de gestão de pessoas do poder executivo na administração pública Federal. V Congresso CONSAD de Gestão Pública. Anais... Brasília - DF, 2012.

PELEIAS, I. R.; EHRENTREICH, H. P.; FERNANDES DA SILVA, A.; FERNANDES, F. C. Pesquisa sobre a percepção dos gestores de uma rede de empresas distribuidoras de um fabricante de autopeças sobre controles internos e gestão de riscos. Gestão, Finanças e Contabilidade, v. 7, n. 1, p. 6 - 28, 2017.

PIERANGELI, M. V.; MACHADO, L. K.; SALES, R. S. Metodologia de gestão de riscos aplicada no apoio à tomada de decisão: abordagem de aspectos da racionalidade limitada. Revista Espacios, v. 38, n. 14, p. 23 - 40, 2017.

RIBEIRO, H. C. M. Produção acadêmica dos artigos publicados em revistas científicas nacionais disponibilizadas na base Atena sobre o tema gestão de riscos de 2000 a 2015 . Revista Evidenciação Contábil \& Finanças, v. 5, n. 1, p. 75 - 93, 2017.

SANTOS, N. M. L.; ANDRADE, D. M.; LIMA, J. B. Valores Públicos e Contratação de Serviços Terceirizados: Desafios no Setor Público. Administração Pública e Gestão Social, v. 11, n. 3, p. 1 - 18, 2019.

SCHIKMANN, R. Gestão estratégica de Pessoas: Bases para a concepção do Curso de Especialização em Gestão de Pessoas no Serviço Público. In Gestão de Pessoas: bases teóricas e experiências no setor público. Brasília, ENAP, 2010. 
SELDEN, S. C. Inovações e tendências globais nas práticas de gestão de recursos humanos. Administração Pública: coletânea. Org. B. Guy Peters e Jon Pierre. São Paulo: Editora UNESP; Brasília, DF: ENAP, 2010.

SILVA, B. J. P. Proposta de Modelo de Gestão de Riscos para uma IFES visando a realização de auditoria baseada em riscos. Natal - RN, 2015.

SNELL, S. A. Administração: construindo vantagem competitiva. $1^{\circ}$ ed. São Paulo: Atlas, 1998.

SOUSA, M. R. B. D. de; FINATI, C. R. D.; PEREZ, M. C.; DUARTE, K. S. B. Gestão de risco nas instituições universitárias: uma análise comparativa da metodologia da Controladoria Geral da União e do Ministério do Planejamento, Desenvolvimento e Gestão. XVIII Colóquio Internacional de Gestión Universitaria. Gestión de la Gobernanza y la Estrategia Orientadas al Desarrollo Sustentable. Anais... Universidad Técnica Particular de Loja - UTPL, Loja, Equador, 2018.

SOUZA, C.; FERNANDES. C. Gestão de riscos e controles internos nas universidades e nos centros universitários do Estado de Santa Catarina: um estudo com apoio da matriz importância-desempenho de Slack. XV Congresso Brasileiro de Custos. Anais... Curitiba PR, Brasil, 2008.

TCU. Tribunal de Contas da União. Risco de exposição a fraude e corrupção na administração, 2018. Disponível em: $<$ https://portal.tcu.gov.br/biblioteca-digital/risco-deexposicao-a-fraude-e-corrupcao-na-administracao.htm>. Acesso em: 18 de mar. 2020.

TCU. Tribunal de Contas da União. Resultados do Levantamento Integrado de Governança Organizacional Pública, 2018a. Disponível em:

$<$ https://portal.tcu.gov.br/governanca/governancapublica/organizacional/levantamento2018/resultados.htm>. Acesso em 11 de fevereiro de 2020.

TCU. Tribunal de Contas da União. Referencial básico de gestão de riscos. Brasília: TCU, Secretaria Geral de Controle Externo (Segecex), 2018 b.

TCU. Tribunal de Contas da União. Secretaria de Métodos e Suporte ao Controle Externo. Gestão de Riscos - Avaliação da Maturidade. Brasília - DF, 2018c.

UnB. Plano de Desenvolvimento Institucional - PDI, 2014. Disponível em: $<$ http://www.dpo.unb.br/images/phocadownload/documentosdegestao/planodesenvinstitucion al/PDI_2014-2017.pdf $>$. Acesso em 13 de fevereiro de 2019.

UnB. Relatório de Gestão, 2016a. Disponível em:

$<$ http://www.dpo.unb.br/images/phocadownload/documentosdegestao/relatoriogestao/Relatrio -de-Gesto-2016.pdf>. Acesso em 09 de fevereiro de 2019.

UnB. Relatório de Gestão DGP, 2016b. Disponível em:

$<$ http://www.dgp.unb.br/images/Documentos/FRelatorio_DGP_2015_2016.pdf $>$. Acesso em 01 de agosto de 2019. 
UnB. Relatório de Gestão, 2018a. Disponível em:

$<$ http://www.dpo.unb.br/images/phocadownload/documentosdegestao/relatoriogestao/2018/R elatrio_de_Gesto_UnB_2018.pdf>. Acesso em 07 de março de 2019.

UnB. Plano de Desenvolvimento Institucional - PDI, 2018b. Disponível em:

$<$ http://www.dpo.unb.br/images/phocadownload/documentosdegestao/planodesenvinstitucion al/PDI-UnB-2018-2022.pdf >. Acesso em 14 de maio de 2019.

UnB. Resolução do Conselho de Administração No 0004/2019, 2019. Disponível: $<$ http://www.dpo.unb.br/images/phocadownload/gestaoriscosintegridade/Anexo_B__Resolu\%C3\%A7\%C3\%A30_0004-2019_Pol\%C3\%ADtica_de_Riscos_e_Integridade.pdf $>$. Acesso em 19 março de 2020. 